\title{
Penyuluhan Pelestarian Mangrove Pada Kelompok Masyarakat Pengawas Pulau Lakkang Di Kecamatan Tallo Kota Makassar Provinsi Sulawesi Selatan
}

\author{
[Extension on Mangrove Conservation to the Community Group monitoring the \\ Lakkang Island in Tallo Sub- District, Makassar City, South Sulawesi Province]
}

\author{
Muhammad Yusril Aditya Mas'ud, Asep Ahmad Subagio, lis Jubaedah
}

Program Studi Penyuluhan Perikanan Politeknik Ahli Usaha Perikanan

Jl. Cikaret No. 2 Bogor Selatan, Kota Bogor

\begin{abstract}
Abstrak
Kecamatan Tallo merupakan salah satu kecamatan di Kota Makassar yang memiliki ekosistem mangrove di Pulau Lakkang. Hutan mangrove merupakan salah satu ekosistem di wilayah pesisir yang mempunyai nilai ekonomi dan ekologi yang tinggi. Kondisinya saat ini mengalami kerusakan akibat pemanfaatannya yang kurang memperhatikan kelestariannya. Kegiatan penelitian ini telah dilakukan pada Bulan Maret sampai dengan Mei 2020. Penelitian ini bertujuan untuk mempelajari perubahan pengetahuan, keterampilan dan sikap pada kelompok masyarakat pengawas (POKMASWAS) dalam melestarikan ekosistem mangrove. Penyuluhan dilakukan menggunakan metode demonstrasi cara, diskusi dan praktik. Sasaran penyuluhan sebanyak 12 orang. Materi penyuluhan adalah cara pembibitan dan penanaman mangrove dan budidaya perikanan yang ramah lingkungan. Data dianalisis secara deskriptif. Hasil evaluasi penyuluhan menunjukkan adanya peningkatan pada aspek pengetahuan pelestarian mangrove dan budidaya ikan yang ramah lingkungan (33\%), aspek keterampilan pembibitan dan penanaman mangrove (28\%) dan sikap sasaran sebelumnya hanya setuju setelah penyuluhan menjadi sangat setuju (18\%).
\end{abstract}

Kata kunci: Kecamatan Tallo; lestari; mangrove; penyuluhan

\section{Abstract}

Tallo Sub-District is one of the sub-districts in Makassar City which, has a mangrove ecosystem on Lakkang Island. Mangrove forest is one of the ecosystems in coastal areas that has high economic and ecological value. The condition is currently experiencing damage due to its use that does not pay attention to its sustainability. This research activity has been carried out from March to May 2020. This research aims to study changes in knowledge, skills, and attitudes of community supervisory groups (POKMASWAS) in conserving mangrove ecosystems. Counseling is carried out using methods of demonstration, discussion and practice. The target of counseling is 12 people. The extension material is an environmentally friendly method of breeding and planting mangroves and aquaculture. Data were analyzed descriptively. The results of the extension evaluation showed an increase in knowledge aspects of environmentally friendly mangrove conservation, and fish cultivation (33\%), aspects of mangrove seeding and planting skills (28\%) and the attitude of the previous target only agreed after counseling became strongly agree

Keywords: sub-district Tallo; sustainbility; mangrove; extention

Penulis Korespondensi

Muhammad Yusril Aditya Mas'ud | ysrlnoerstan@gmail.com 


\section{PENDAHULUAN}

Kecamatan Tallo merupakan salah satu kecamatan di Kota Makassar yang berpotensi untuk pengembangan usaha perikanan. Luas wilayah Kecamatan Tallo sekitar $8,75 \mathrm{~km}^{2}$ yang terdiri dari 15 kelurahan. Letak geografisnya berbatasan dengan Kecamatan Tamalanrea di bagian utara dan barat, Kecamatan Panakukkang dibagian selatan dan Kecamatan Bontoala dan Kecamatan Ujung Tanah dibagian timur. Ketersediaan lahan budidaya dan pasokan air yang berasal dari Sungai Tallo dan Sungai Pampang yang memadai untuk kegiatan perikanan di daerah ini menjadikan kecamatan ini sebagai salah satu sektor perikanan yang berpotensi untuk dikembangkan. Selain potensi perikanan yang memadai, daerah ini juga memiliki Kawasan Konservasi Perairan yaitu Pulau Lakkang dan terdapat 1 Kelompok Masyarakat Pengawas Mangrove dengan jumlah 20 RTP.

Menurut (Mas'ud 2019) permasalahan yang ada di Pulau Lakkang yaitu masih maraknya pemanfaatan hutan mangrove untuk dijadikan kayu bakar dan bahan bangunan serta alih fungsi lahan menjadi tambak yang tidak memperhatikan kelestariannya. Hal tersebut diakibatkan oleh masih kurangnya pengetahuan, keterampilan dan sikap masyarakat mengenai fungsi dan manfaat ekosistem mangrove. Kondisi perairan sekitarnya yang sudah mulai tercemar akibat pencemaran limbah cair dari pabrik gula dan rumah tangga yang bermuara ke Pulau Lakkang hal ini menyebabkan kualitas perairan yang menurun. Penurunan kualitas perairan di ekosistem mangrove mengakibatkan produksi budidaya polikultur udang dan bandeng yang menurun. Selain itu berkurangnya biota perairan seperti rajungan (Portunidae) yang merupakan mata pencaharian nelayan di sekitar Pulau Lakkang. Hasil tangkapan nelayan rata-rata hanya mendapatkan 6,3 kg/hari.

Ekosistem mangrove atau yang sering disebut hutan bakau merupakan sebagian wilayah ekosistem pantai yang mempunyai karakter unik dan khas, dan memiliki potensi kekayaan hayati (Mulyadi, Laksmono, dan Aprianti 2009) selain itu mangrove mempunyai peranan penting baik secara ekologi maupun secara ekonomi. Secara ekologi mangrove merupakan habitat berbagai jenis organisme air, sebagai tempat pemijahan, pembesaran selain itu sebagai penahan erosi dan abrasi pantai juga dapat mencegah intrusi air laut. Secara ekonomi ekosistem mangrove merupakan habitat berbagai jenis ikan, udang dan rajungan yang memiliki nilai ekonomis penting. 
Menurut (Adriman et al. 2020) pemahaman yang mendalam masyarakat terhadap pentingnya ekosistem mangrove masih sangat kurang. Pengelolaan ekosistem mangrove berbasis masyarakat masih belum banyak diketahui. Masyarakat belum mengetahui sistem pengelolaan ekosistem mangrove yang tidak merusak lingkungan dan dapat dijadikan potensi ekowisata, khususnya kelompok masyarakat pengawas di Pulau lakkang. Untuk meningkatkan pengetahuan, keterampilan dan sikap terhadap kelompok masyarakat pengawas, maka penyuluhan pelestarian, pembibitan dan penanaman mangrove merupakan salah satu cara untuk membangun kesadaran masyarakat agar lebih peduli lingkungan dan menjaga ekosistem mangrove. Tujuan penelitian adalah untuk mempelajari perubahan pengetahuan, keterampilan dan sikap pada Kelompok Masyarakat Pengawas (POKMASWAS) tentang pelestarian mangrove dan budidaya ikan ramah lingkungan.

\section{BAHAN DAN METODE}

Penelitian ini dilaksanakan pada bulan Maret sampai dengan Mei 2020, bertempat di Pulau Lakkang Kecamatan Tallo Kota Makassar Provinsi Sulawesi Selatan. Jenis data yang dikumpulkan yaitu data primer dan data sekunder. Data kemudian dianalisis secara deskriptif Materi penyuluhan yang disampaikan adalah mengenai cara pembibitan, penanaman mangrove dan budidaya perikanan yang ramah lingkungan. Sebelum penyuluhan, dilakukan sosialisasi terlebih dahulu. Sosialisasi ini bertujuan untuk memberikan pemahaman dan penjelasan awal kepada sasaran maupun seluruh pihak/instansi yang terlibat pelaksanaan beberapa program penyuluhan. Penyuluhan dilakukan selama 9 minggu. Metode penyuluhan yang digunakan yaitu demontrasi cara, diskusi dan anjangsana. Penyuluhan dilakukan secara partisipatif dimana sasaran dilibatkan dalam kegiatan penyuluhan pelestarian mangrove mulai dari tahap persiapan, pelaksanaan dan evaluasi. Menurut Mustanir, Hamid, dan Syarifuddin (2019) penyuluhan partisipatif yaitu melibatkan pembudidaya dalam perencanaan, pelaksanaan dan evaluasi. Peralatan untuk penyuluhan antara lain; lembar persiapan menyuluh (LPM), folder, video, softcopy file berbentuk powerpoint, dan model/benda nyata. Bahan-bahan yang digunakan untuk demontrasi cara pembibitan dan penanaman mangrove yaitu buah mangrove jenis rhizophora dan avicenia, benih mangrove, lumpur, cetok, tali rapia, bambu, alat ukur, polybag dan bedeng. Sasaran penyuluhan sebanyak 12 orang yang tergabung dalam kelompok masyarakat pengawas. 


\section{Demonstrasi Cara Pembibitan dan Penanaman Mangrove}

Kegiatan demonstrasi cara pembibitan dan penanaman mangrove dilaksanakan pada Kelompok Masyarakat Pengawas (POKMASWAS) Batu Doang. Cara pembibitan dan penanaman mangrove mengikuti panduan praktis teknik rehabilitasi mangrove (Priyono 2010). Pembibitan: penyiapan tempat persemaian, penyiapan media, pembuatan bedeng semai, pengadaan buah (propagul), Penyemaian dan penanaman. Pembibitan dilakukan dengan dua teknik yaitu teknik dengan polybag dan teknik dengan bedengan (Hiariey dan Kaihatu 2012).

\section{Sosialisasi Budidaya Perikanan yang Ramah Lingkungan}

Kegiatan sosialisasi budidaya yang ramah lingkungan dilakukan terhadap anggota kelompok masyarakat pengawas di Pulau lakkang. Tujuan sosialisasi ini untuk meningkatkan kesadaran masyarakat akan pentingnya pelestarian mangrove. Kegiatan sosialisasi budidaya perikanan yang ramah lingkungan dilakukan karena masih rendahnya pengetahuan dan pemahaman yang mendalam tentang pentingnya peran dan fungsi mangrove dalam ekosistem pesisir, hal ini yang mendorong pemanfaatan mangrove yang tidak terkendali dan budidaya perikanan yang tidak berkelanjutan. Materi yang diberikan berupa sosialisasi mengenai cara budidaya ikan yang ramah lingkungan yang terdapat pada regulasi pemerintah Undang-Undang Nomor 31 Tahun 2004 jo Undang-Undang Nomor 45 Tahun 2009 Tentang Perikanan dan Peraturan Pemerintah Nomor 60 Tahun 2007 tentang Konservasi Sumber Daya Ikan.

\section{Evaluasi penyuluhan}

Hasil evaluasi kegiatan penyuluhan dianalisis menggunakan perhitungan (Nurjaman, Sobariah, dan Supenti 2018). Evaluasi penyuluhan dilakukan pada akhir kegiatan penyuluhan untuk mengetahui respons sasaran terhadap penyuluhan yang telah dilakukan, menggunakan alat bantu berupa lembar kuesioner. Evaluasi dilakukan pada saat sebelum dan sesudah penyuluhan. Evaluasi dilakukan terhadap aspek sikap, pengetahuan dan keterampilan yang diamati selama 9 minggu. Menurut Mardikanto (2011) kegiatan evaluasi dilakukan terhadap 2 aspek, yaitu pengetahuan dan sikap (menggunakan skala Likert). Dari hasil evaluasi kemudian dihitung nilai perubahannya dan peningkatannya menggunakan perhitungan sebagai berikut:

$$
\begin{gathered}
\text { Perubahan }=\text { Nilai Akhir }- \text { Nilai Awal } \\
\text { Peningkatan }=\frac{\text { Nilai Akhir }- \text { Nilai Awal }}{\text { Nilai Awal }} \times 100 \% \\
\text { Aspek sikap }=\frac{\text { Total Nilai Skor }}{\text { Total Nilai Maksimal }} \times 100 \%
\end{gathered}
$$


HASIL DAN PEMBAHASAN

Hasil

Deskripsi Lokasi

Pulau Lakkang merupakan kelurahan terluas di Kecamatan Tallo dengan luas 165 ha atau $1650000 \mathrm{~m}^{2}$ dan terletak pada pada $119^{\circ} 27^{\prime} 43.8$ bujur timur dan $5^{\circ} 07^{\prime} 44.7$ lintang selatan. Di sepanjang delta tersebut merupakan kawasan lindung yang ditetapkan dalam Peraturan Daerah Kota Makassar Nomor 4 Tahun 2015 Tentang RTRW Kota Makassar Tahun 2015. Ekosistem mangrove di daerah ini memiliki luas 10 ha atau $10000 \mathrm{~m}^{2}$ (6,06\%). Jenis mangrove dominan yaitu Bakau (Rhizophora apiculata), Api-Api (Avicennia alba), dan Nipah (Nypa fruticans). Untuk kegiatan perikanan budidaya terdapat tambak dan sawah seluas 122 ha dengan komoditas polikultur budidaya Udang Windu (Penaeus monodon) atau Udang Vannamei (Litopenaeus vannamei) dengan ikan bandeng (Chanos chanos) untuk tambak dan padi (Oryza sativa) untuk sawah, dan terdapat 1,25 ha untuk kebun campuran yang didominasi oleh Pohon Bambu (Bambuseae). Kondisi mangrove saat ini sudah mengalami kerusakan akibat alih fungsi lahan, penebangan pohon untuk kayu bakar, bahan bangunan dll. Kualitas perairan mulai menurun karena ada pencemaran dari limbah rumah tangga maupun limbah cair dari pabrik gula.
Jumlah penduduk yang terdapat di Pulau Lakkang yaitu sebanyak 905 jiwa dengan jumlah laki - laki sebanyak 438 jiwa dan perempuan sebanyak 467 jiwa. Tingkat pendididkan SD $(39,4 \%)$, SMP (13,8\%), SMA (15,5\%) DIPLOMA dan sarjana $(1,8 \%)$. Jumlah rumah tangga perikanan (RTP) sebanyak 166 RTP yang terdiri dari 100 RTP pembudidaya udang yang dibagi menjadi 10 POKDAKAN, 46 RTP nelayan yang belum berkelompok, dan 1 kelompok masyarakat pengawas mangrove dengan jumlah 20 RTP yang diketua oleh bapak Saraba (Mas'ud 2019).

\section{Karakteristik Sasaran}

Karakteristik sasaran penyuluhan pada kelompok masyarakat pengawas di Pulau Lakkang dapat dilihat pada Tabel 1. Tabel 1 memperlihatkan karakteristik sasaran berada pada rentang usia 24 - 60 tahun yaitu. merupakan usia yang produktif. Hal ini menunjukkan potensi tersedianya tenaga kerja di kawasan mangrove bagi upaya pengelolaan hutan mangrove.dilihat dari faktor usia, masyarakat di sekitar hutan mangrove merupakan sumberdaya manusia yang potensial untuk dikembangkan dan ditingkatkan kemampuannya dalam upaya pelestarian hutan mangrove. Hermawan (2017) mengatakan usia produktif mempengaruhi produktivitas kerjanya dalam mengelola suatu kegiatan. Selain 
Tabel 1. Karakteristik Sasaran

\begin{tabular}{llccc}
\hline No. & Nama & $\begin{array}{c}\text { Usia } \\
\text { (Tahun) }\end{array}$ & $\begin{array}{c}\text { Tingkat } \\
\text { Pendidikan }\end{array}$ & $\begin{array}{c}\text { Pengalaman } \\
\text { Berkelompok } \\
\text { (Tahun) }\end{array}$ \\
\hline 1. & Saraba & 56 & SMA & 5 \\
2. & Idris & 36 & SD & 5 \\
3. & Rumallang & 27 & SMP & 3 \\
4. & Nasrullah & 35 & SMP & 5 \\
5. & Baharuddin & 60 & SD & 4 \\
6. & Akmal & 24 & SMA & 3 \\
7. & Nurdin Jalali & 50 & Tidak sekolah & 2 \\
8. & Kadir & 50 & Tidak sekolah & 2 \\
9. & Amiruddin & 30 & SD & 4 \\
10. & Majido & 50 & Tidak sekolah & 4 \\
11. & Sumang & 34 & SD & 3 \\
12. & Kaseng & 55 & SD & 4 \\
\hline
\end{tabular}

itu umur produktif umumnya memiliki semangat untuk ingin tahu dan aktif berusaha mencari informasi. Pada tingkat pendidikan, sasaran memiliki tingkat pendidikan mulai dari yang tidak mengenyam pendidikan hingga yang paling tinggi yaitu SMA, tingkat pendidikan berpengaruh terhadap cara pandang dan pola pikir sasaran terhadap sebuah inovasi.

\section{Demonstrasi Cara Pembibitan dan} Penanaman Mangrove

Kegiatan demonstrasi cara pembibitan dan penanaman mangrove dilaksanakan pada kelompok masyarakat pengawas (POKMASWAS) Batu Doang di Pulau Lakkang. Kegiatan Demonstrasi cara dilakukan secara partisipatif, dihadiri oleh anggota kelompok sebanyak 12 orang mulai dari persiapan hingga tahap akhir. Adapun tahapan kegiatan yang dilakukan pada proses demcar ini meliputi: a) Penentuan Lokasi

Sebelum dilakukan pembibitan dan penanaman maka terlebih dahulu ditentukan lokasi tempat dilakukan penyemaian bibit dan penanaman kembali (Replanting) mangrove atau penyulaman mangrove. Lokasi yang digunakan dalam kegiatan ini menyesuaikan dengan jenis mangrove yang akan ditanam dengan kondisi lingkungannya, adapun kondisi lingkungan yang terdapat pada proses demcar penanaman mangrove ini berada di pesisir Pulau Lakkang seluas $20 \mathrm{~m}^{2}$ dengan kedalaman air jika surut berkisar $30 \mathrm{~cm}-60 \mathrm{~cm}$ dan pasang berkisar $100 \mathrm{~cm} \mathrm{-} 120 \mathrm{~cm}$, suhu berkisar $28^{\circ} \mathrm{C}-31^{\circ} \mathrm{C}$, substrat dasar perairan berupa tanah liat berlumpur dengan salinitas perairan berkisar 10-25ppm. Jenis mangrove yang mendominasi di Pulau Lakkang 

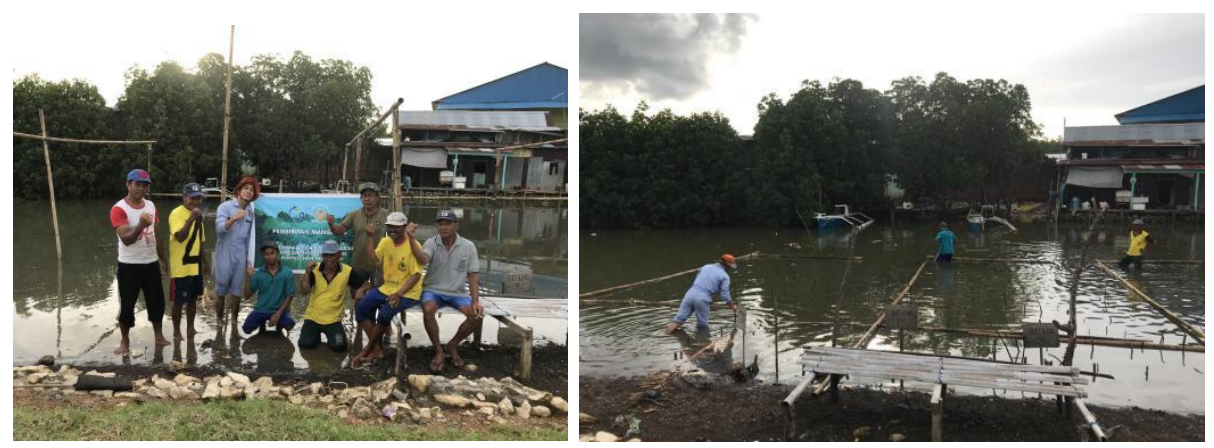

Gambar 1. Lokasi Demcar Pembibitan dan bedeng semai
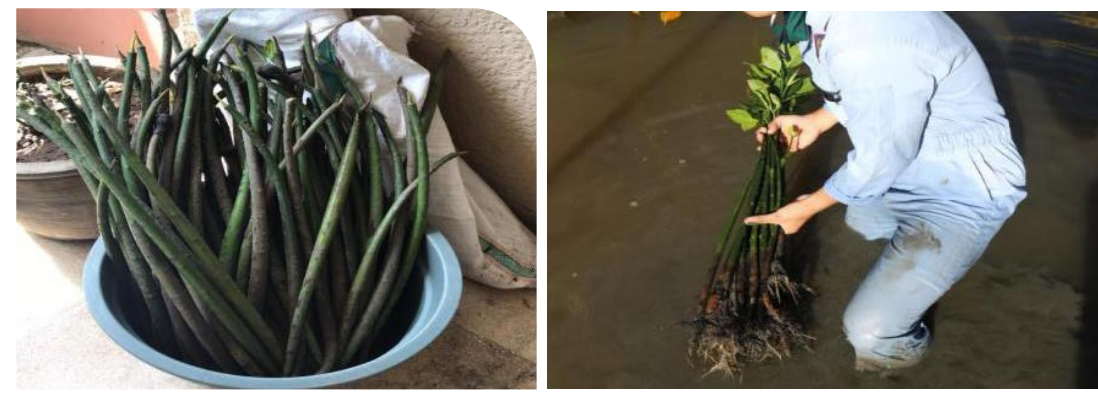

Gambar 2. Propagul dan Bibit mangrove Api- Api (Avicennia alba)

diantaranya Api-Api (Avicennia alba), Bakau (Rhizophora apiculata), dan Nipah (Nypa fruticans). Lokasi tempat dilakukan pembibitan, bedeng semai dan penanaman mangrove dapat dilihat pada Gambar 1 .

b) Pembuatan Bedeng Semai Bedeng semai dibuat dengan ukuran $20 \times 10$ m memakai bambu sebagai rangkanya dan ditutupi oleh paranet sebagai naungan, cahaya matahari tidak semuanya langsung mengenai bibit mangrove yang sudah disusun di dalam bedeng serta dapat mengurangi paparan cahaya matahari $50-60 \%$.

c) Pemilihan Jenis Mangrove
Pemilihan jenis mangrove yang akan disemai dan ditanam kembali di lokasi yaitu jenis yang sesuai dengan karakteristik lingkungan, jenis yang mendominasi sehingga mudah untuk didapatkan serta memiliki fungsi bagi masyarakat sekitar melihat dengan kondisi lingkungannya jenis mangrove Api-Api (Avicennia alba). Selain sesuai dengan kondisi lingkungan dan jumlahnya yang mendominasi di Pulau Lakkang batang, getah, dan biji Api - Api (Avicennia alba) juga sering digunakan oleh masyarakat sekitar sebagai obat luka bakar. Hal ini senada dengan pernyataan Ghufron 


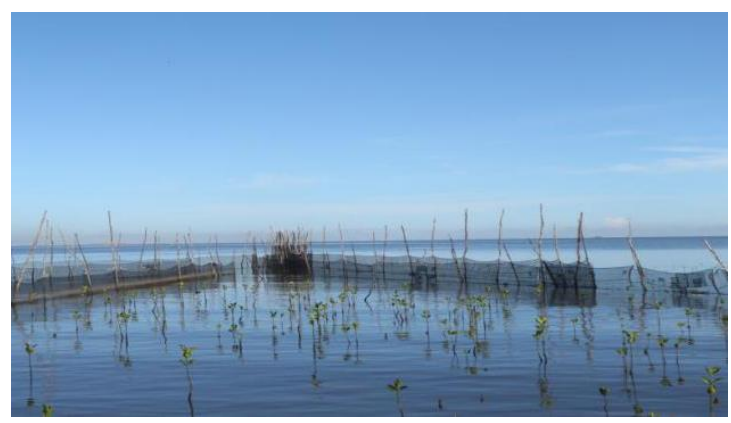

Gambar 3. Pemecah Gelombang (Apo)

dan Kordi (2012), bahwa jenis Avicennia alba dapat dijadikan sebagai obat sakit gigi, luka bakar.Gambar jenis mangrove Api Api (Avicennia alba) yang ditanam dapat dilihat pada Gambar 2.

d) Pemasangan Pemecah Gelombang (Apo)

Menurut Priyono (2010) mangrove baru bisa berfungsi sebagai penahan abrasi setelah berumur kurang lebih lima tahun disaat akarnya telah kuat sehingga mampu mengurangi kekuatan gempuran gelombang, sehingga dalam proses penanaman bibit sebaiknya perlu dilakukan pemasangan pemecah gelombang atau apo agar bibit yang ditanam tidak hanyut oleh gelombang pantai. Pemasangan apo atau pemecah gelombang di lokasi penanaman mangrove sepanjang $50 \mathrm{~m}$ yang bertujuan agar bibit mangrove yang ditanam tidak terhempas oleh gelombang air, konstruksi apo ini terbuat dari bambu atau kayu yang dipasang secara melintang kemudian dililitkan oleh paranet atau jaring bekas alat tangkap nelayan yang berada di lintasan gelombang air. Bentuk apo yang dibuat pada saat Praktik Akhir dapat dilihat pada Gambar 3.

e) Penanaman Kembali (Replanting) Mangrove

Penanaman dilakukan pada lokasi yang sebelumnya telah ditentukan, penanaman dilakukan pada pukul 06.00-08.00 ketika air masih surut sehingga lebih mudah dalam menjangkau lokasi penanaman yang bersubstrat tanah liat berlumpur dengan jumlah biibit yang ditanam yaitu sebanyak 200 buah bibit mangrove jenis Rhizophora apiculata.

Menurut Priyono (2010) tahapan dalam penanaman bibit mangrove terdiri dari (1) Pengambilan bibit mangrove dari bedeng semai, (2) membuka polybag yang menutupi sedimen dan akar bibit, penyimpanan polybag di wadah agar 

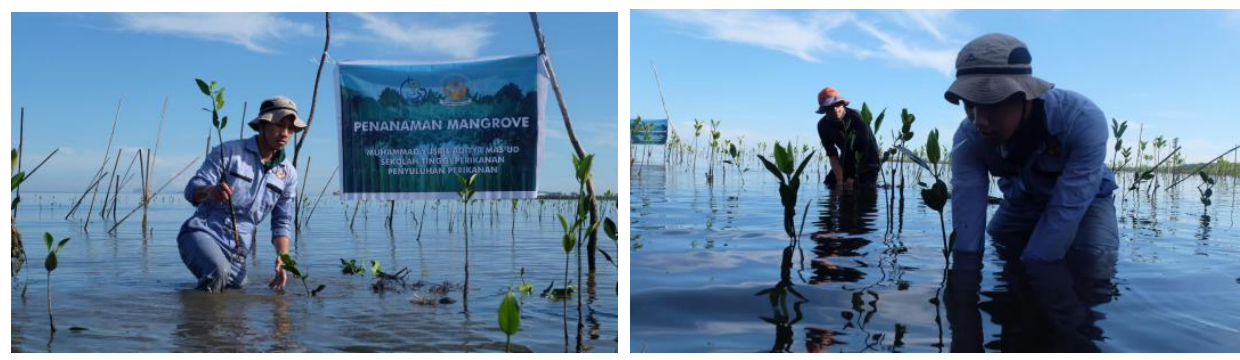

Gambar 4. Penanaman Kembali (Replanting) Mangrove

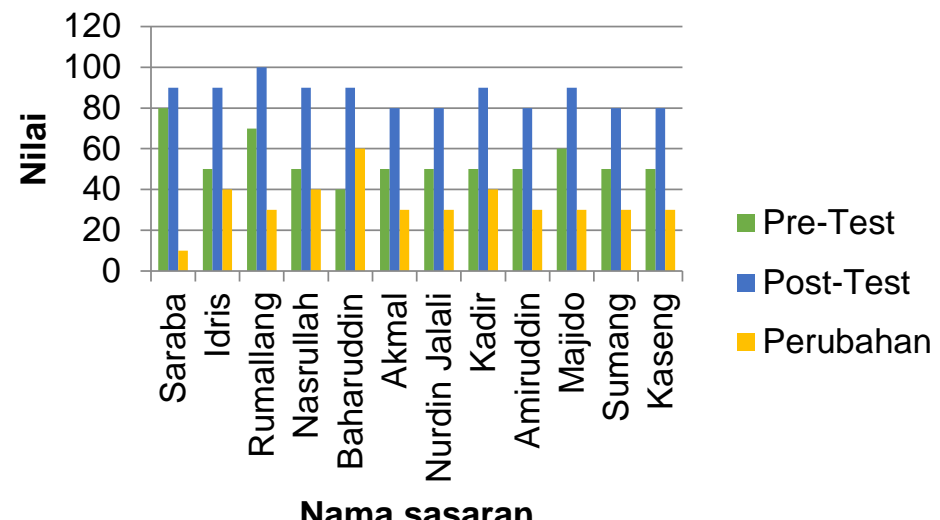

Gambar 5. Diagram hasil evaluasi pengetahuan demcar penanaman mangrove

tidak menjadi sampah plastik di lokasi penanaman yang akan diangkat ke daratan, (3) menanam bibit mangrove ke tanah dengan cara melubangi tanah memakai cetok hingga cukup dalam agar akar mangrove dapat tertanam dengan baik atau dapat ditanam dengan cara ditancap secara langsung jika berada di lingkungan yang tergenang, (4) ikat bibit mangrove ke kayu penyangga (ajir) memakai tali rafia, (5) Tekan tanah perlahan agar tanah menjadi padat dan bibit menjadi berdiri tegak. Proses penanaman kembali (Replanting) mangrove yang dilakukan secara partisipatif bersama anggota kelompok dapat dilihat pada Gambar 4.

\section{Hasil Evaluasi Aspek Pengetahuan}

Gambar 5 menunjukkan hasil evaluasi yang diberikan kepada 12 orang responden diperoleh hasil nilai rata-rata evaluasi awal sebesar 54 dan terjadi perubahan sebesar 33 sehinngga nilai rata-rata evaluasi akhir menjadi 87 atau terjadi peningkatan sebesar 33\%.

Hasil Evaluasi Aspek Sikap

Sebelum kegiatan penyuluhan sasaran termasuk dalam kategori setuju 


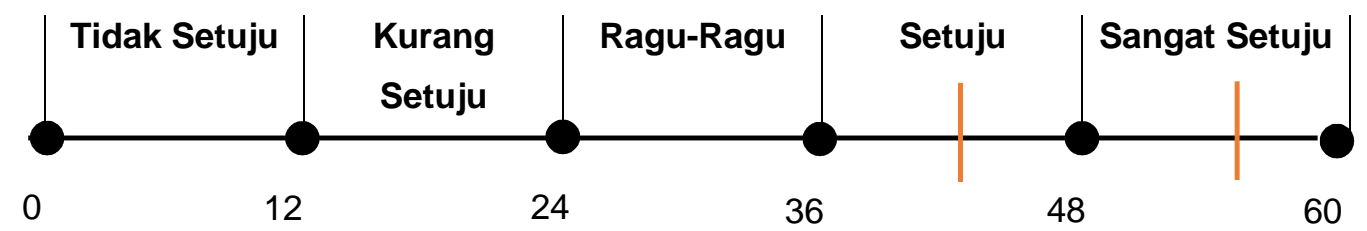

Gambar 6. Garis kontinum evaluasi sikap demcar penanaman mangrove

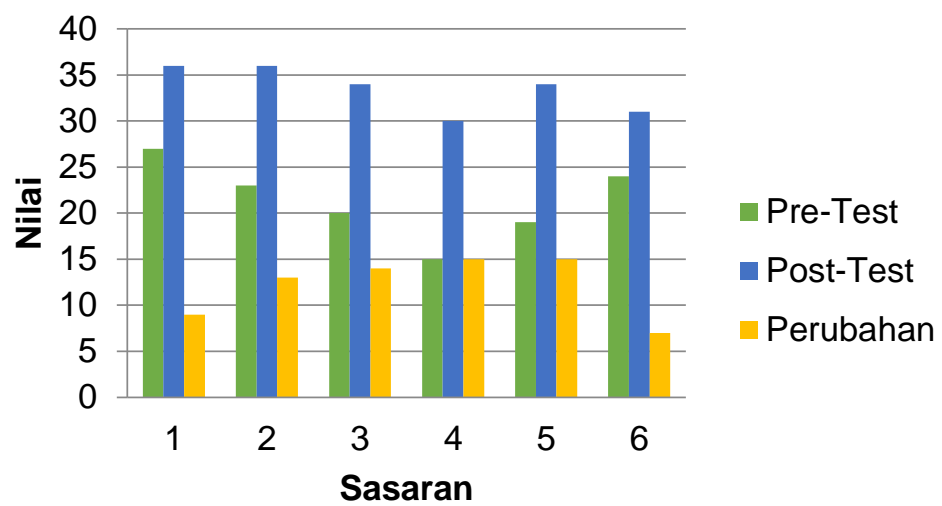

Gambar 7. Evaluasi keterampilan pembibitan dan penanaman mangrove

sedangkan setelah dilaksanakan kegiatan penyuluhan sasaran termasuk dalam kategori sangat setuju.

\section{Hasil Evaluasi Aspek Keterampilan}

Berdasarkan hasil rekapitulisai aspek keterampilan mengenai pembibitan dan penanaman mangrove diperoleh nilai rata-rata evaluasi awal sebesar 21 dan terjadi perubahan sebesar 10 sehingga diperoleh nilai akhir sebesar 33,5 atau mengalami peningkatan sebesar rata-rata $28 \%$.

\section{Penyuluhan Pembibitan dan Penanaman Mangrove}

Hasil evaluasi program penyuluhan secara langsung melalui demontrasi cara pembibitan dan penanaman mangrove menunjukkan bahwa terjadi peningkatan pengetahuan, sikap, dan keterampilan kelompok masyarakat pengawas (POKMASWAS) Batu Doang dalam pembibitan dan penanaman mangrove. Perbandingan kondisi sebelum dan sesudah dilakukan penyuluhan dapat di lihat pada Tabel 2.

\section{Sosialisasi Budidaya Perikanan yang Ramah Lingkungan}

Kegiatan sosialisasi budidaya perikanan yang ramah lingkungan perlu dilakukan mengingat banyaknya lahan yang dialih fungsikan dari yang sebelumnya merupakan hutan mangrove kemudian dijadikan sebagai pemukiman dan 
Tabel 2. Indikator, Perubahan pengetahuan, keterampilan dan sikap dalam Pembibitan dan Penanaman Mangrove

\begin{tabular}{|c|c|c|}
\hline & ebelum & dah \\
\hline $\begin{array}{l}\text { infaat } \\
\geq \text { bagi }\end{array}$ & $\begin{array}{l}\text { Kelompok masih kurang } \\
\text { mengetahui fungsi dan } \\
\text { manfaat mangrove } \\
\text { sehingga } \\
\text { memanfaatkan mangrove } \\
\text { secara berlebihan seperti } \\
\text { menjadi kayu bakar dan } \\
\text { bahan bangunan, alif } \\
\text { fungsi lahan untuk tambak } \\
\text { yang tidak ramah } \\
\text { lingkungan }\end{array}$ & $\begin{array}{l}\text { Anggota kelompok mulai } \\
\text { sadar pentingnya } \\
\text { pelestarian mangrove, } \\
\text { sasaran mengetahui peran } \\
\text { dan fungsi mangrove } \\
\text { sasaran mulai melakukan } \\
\text { pemanfaatan mangrove } \\
\text { secara terkendali }\end{array}$ \\
\hline ipat & $\begin{array}{l}\text { Hanya memakai lahan } \\
\text { basah yang terkena } \\
\text { gelombang pasang di } \\
\text { tepian sungai }\end{array}$ & $\begin{array}{l}\text { Dibuatkan tempat } \\
\text { persemaian dengan luas } 20 \\
\times 10 \mathrm{~m} \text { sehingga dapat } \\
\text { menampung bibit lebih dari } \\
2000 \text { bibit }\end{array}$ \\
\hline ve & $\begin{array}{l}\text { Buah (Propagul) hanya di } \\
\text { tancapkan ditepian sungai } \\
\text { yang memiliki substrat }\end{array}$ & $\begin{array}{l}\text { Ditanam memakai media } \\
\text { substrat yang didapat dari } \\
\text { tepian sungai dan } \\
\text { dimasukkan ke dalam } \\
\text { polybag }\end{array}$ \\
\hline \multirow[t]{3}{*}{ buah } & $\begin{array}{l}\text { Buah (Propagul) diambil } \\
\text { yang telah jatuh disekitar } \\
\text { tepian sungai }\end{array}$ & $\begin{array}{l}\text { Buah (Propagul) diambil } \\
\text { yang telah jatuh disekitar } \\
\text { tepian sungai dan dipetik } \\
\text { dari pohon yang dianggap } \\
\text { sudah matang dan siap } \\
\text { untuk disemai }\end{array}$ \\
\hline & $\begin{array}{l}\text { Bibit ditanam tidak } \\
\text { memakai kayu penyangga } \\
\text { sehingga banyak bibit yang }\end{array}$ & $\begin{array}{l}\text { Dipasangkan kayu } \\
\text { penyangga agar bibit tidak } \\
\text { mudah terhempas oleh arus }\end{array}$ \\
\hline & $\begin{array}{l}\text { elompas oleh arus } \\
\text { elombang }\end{array}$ & $\begin{array}{l}\text { gelombang hingga akarnya } \\
\text { kokoh }\end{array}$ \\
\hline
\end{tabular}

tambak budidaya perikanan. Kegiatan budidaya ikan yang dilakukan oleh masyarakat yaitu polikultur udang dan bandeng

Wanamina (Silvofishery) merupakan salah satu model pengelolaan ekosistem mangrove yang memadukan antara aspek ekologi dan aspek ekonomi. Aspek ekologi sebagai upaya melestarikan ekosistem mangrove agar berkelanjutan, sedangkan aspek ekonomi sebagai upaya untuk memanfaatkan tambak secara optimal. Secara umum pola silvofishery yang telah dipraktikkan di Indonesia selama ini seperti yang telah dikemukakan Bengen (2001) yaitu sebagai berikut: (1) empang parit, (2) empang parit yang disempurnakan, dan (3) komplangan. Ketiga pola tersebut masing-masing mempunyai kelebihan dan kekurangan. Dengan rasio $40 \%$ mangrove dan $60 \%$ tambak pada tambak wanamina (silvofishery) apabila dikelola secara profesional dengan menerapkan 


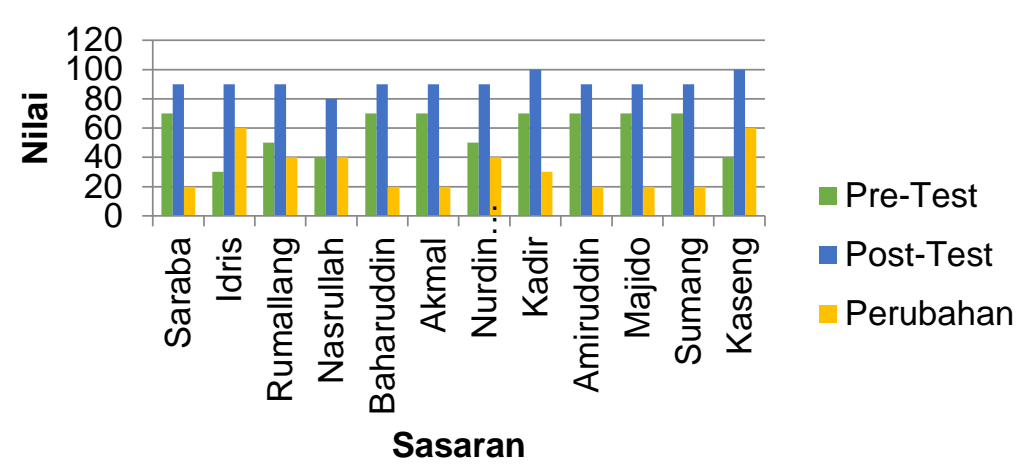

Gambar 8. Diagram hasil evaluasi pengetahuan sasaran terhadap budidaya ramah lingkungan

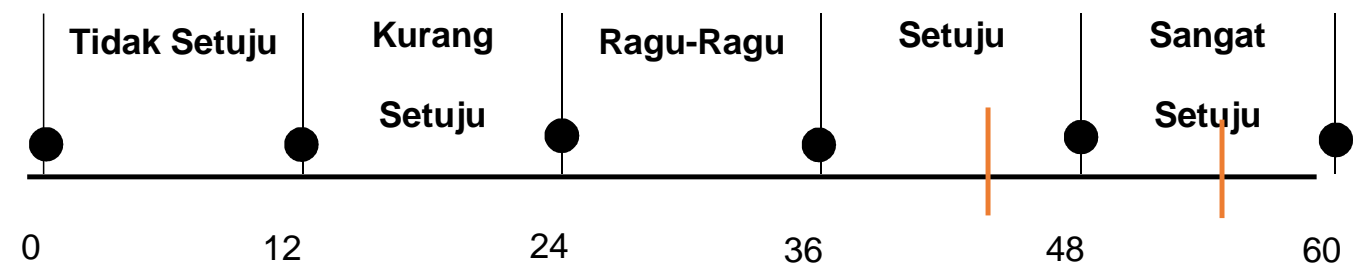

Gambar 9. Garis kontinum evaluasi sikap sasaran terhadap budidaya ramah lingkungan

budidaya sistem polikultur udang, ikan dan kepiting.

\section{Hasil Evaluasi Aspek Pengetahuan}

Gambar 8 menunjukkan hasil nilai rata-rata evaluasi awal sebesar 58 dan terjadi perubahan sebesar 33 sehinngga nilai rata-rata evaluasi akhir menjadi 91 atau terjadi peningkatan sebesar $33 \%$.

\section{Hasil Evaluasi Aspek Sikap}

Pada garis kontinum (Gambar 9) memperlihatkan bahwa sebelum kegiatan penyuluhan sasaran termasuk dalam kategori setuju sedangkan setelah dilaksanakan kegiatan penyuluhan sasaran termasuk dalam kategori sangat setuju.

\section{Pembahasan}

Rendahnya tingkat pendidikan, mendorong pemanfaaatan potensi sumber daya alam yang tidak berkelanjutan. Kegiatan penebangan mangrove, alih fungsi lahan menjadi pertambakan, pemukiman yang dilakukan oleh masyarakat untuk memenuhi kebutuhan masyarakat berpengaruh terhadap kelestarian sumber daya perikanan yang menjadi mata pencaharian pokok bagi 
masyarakat. Menurut Raymond, Harahap, dan Soemarno (2010) ekosistem mangrove merupakan salah satu ekosistem wilayah pesisir yang mengalami tingkat degradasi yang cukup tinggi akibat pola pemanfaatan lingkungan yang cenderung tidak ramah lingkungan. Berkembangnya aktivitas masyarakat di sekitar kawasan mangrove di kawasan konservasi Batu Doang secara langsung atau tidak langsung akan berpengaruh terhadap ekosistem di sekitarnya khususnya hutan bakau dan organisme perairan yang hidup di sekitarnya. Penyuluhan pelestarian mangrove terhadap kelompok masyarakat pengawas merupakan salah satu cara yang dapat dilakukan dalam usaha membuat kawasan pesisir khususnya kawasan konservasi di Pulau Lakkang semakin baik dan sangat penting diberikan terutama kepada masyarakat yang berdomisili dan dalam kehidupannya berkaitan dengan mangrove dan wilayah pesisir.

Menurut Pawestri (2018), kesadaran masyarakat merupakan kekuatan yang sangat ampuh dalam menjaga kelestarian hutan mangrove. Kesadaran terhadap lingkungan merupakan akibat dari berkembangnya pemahaman terhadap lingkungan itu sendiri maupun akibat terjadinya perubahan nilai-nilai yang dianut, sikap dan karakeristik individu. Antara pandangan manusia terhadap kelestarian lingkungan terdapat keterkaitan yang sangat erat. Pandangan manusia terhadap lingkungan tergantung dari pengetahuan dan pengalaman yang diperolehnya. Kusumawardani (2012) mengatakan bahwa faktor-faktor yang mempengaruhi tingkat pengetahuan, sikap dan praktik seseorang di antaranya intelegensia, pendidikan, pengalaman, usia, tempat tinggal, pekerjaan, tingkat ekonomi, sosial budaya dan informasi.

Upaya pelestarian belum banyak dilakukan di kawasan konservasi Pulau lakkang, padahal ekosistem mangrove sangat penting artinya dalam pengelolaan sumber daya pesisir. Mangrove atau mangal adalah sebutan umum yang digunakan untuk menggambarkan suatu varietas komunitas pantai tropik yang didominasi oleh beberapa spesies pohon-pohon yang khas atau semaksemak yang mempunyai kemampuan untuk tumbuh dalam perairan asin (Nybakken 1997). Mangrove juga merupakan salah satu tumbuh-tumbuhan tanah timbul yang tahan terhadap salinitas laut terbuka (Odum 1994). Beberapa jenis pohon mangrove yang tumbuh dan berkembang pada daerah pasang surut pantai berlumpur (Bengen 2000). Jenis mangrove yang dominan di Pulau Lakkang adalah Rizhopora sp, Avicenia sp dan Bruguiera sp.

Perairan yang ditumbuhi hutan bakau sangat subur karena banyak 
bahan organik dari penguraian daun. Daun-daun yang berjatuhan dan mengendap di dasar perairan akan menjadikan substrat yang baik bagi bakteri dan jamur untuk membantu proses pembusukan. Daun yang busuk akan menjadi bahan organik sederhana sebagai makanan Amphipoda dan satwa renik lainnya, dan satwa renik ini menjadi makanan bagi ikan dan udang (Dahuri et al. 1996). Kerusakan dapat menurunkan fungsi hutan mangrove baik secara bioekologis berupa rusaknya ekosistem maupun fungsi ekonomis berupa penurunan produksi. Berdasarkan hasil wawancara dengan ketua POKMASWAS bapak Saraba produksi hasil tangkapan menurun, nelayan hanya memperoleh hasil tangkapan rata-rata sekitar 6,3 $\mathrm{kg} /$ hari. Produksi penangkapan ikan di Pulau Lakkang yaitu memakai kapal dengan ukuran $7 \mathrm{~m}$ x 1,5 m berkapasitas < 1 GT yang disebut kantinting dan memakai mesin tempel 1 - 2 PK berbahan bakar solar dengan alat tangkap yaitu bubu (trap) untuk target tangkapan berupa rajungan (Portunidae) dan kerang-kerangan, serta hewan dasar perairan.

\section{Program Penyuluhan Pembibitan dan} Penanaman Mangrove

Berdasarkan hasil evaluasi (Tabel 2) dapat di lihat perubahan terhadap sasaran yaitu POKMASWAS Batu Doang sebelum dilakukannya penyuluhan sasaran belum mengetahui peran dan fungsi mangrove, belum terampil dalam memilih bibit yang siap di tanam, dan cara menanam serta pemeliharaannya. Oleh karena itu, mangrove dimanfaatkan secara berlebihan dan setelah dilakukan demonstrasi cara pembibitan dan penanaman mangrove sasaran telah dapat menyikapi dengan cukup baik sasaran yang tadinya hanya setuju setelah kegiatan demontrasi cara pembibitan dan penanaman mangrove menunjukkan sikap sangat setuju karena masyarakat sudah mengetahui fungsi dan manfaat mangrove bagi lingkungan disekitarnya. Sebagian besar anggota kelompok telah berusaha melakukan penanaman mangrove namun mereka belum mengetahui benar teknis cara pembibitan dan penanaman, jenis mangrove apa yang sesuai. Kesadaran masyarakat dalam pelestarian ekosistem mangrove sudah menunjukkan hasilnya, masyarakat mulai berupaya untuk melakukan pembibitan dan penanaman mangrove lebih luas lagi, untuk mengurangi abrasi pantai dan meningkatkan produksi hasil budidaya maupun hasil tangkapan ikan, udang dan rajungan yang menjadi mata pencaharian masyarakat di sekitar kawasan konservasi Batu Doang.

Usia sasaran penyuluhan merupakan usia produktif antara $24-60$ tahun sehingga sasaran tidak sulit menerima pengetahuan, keterampilan dan sikap 
tentang cara pembibitan dan penanaman mangrove Penyuluhan mampu mengubah keadaan sasaran menjadi lebih meningkat pengetahuan, sikap dan keterampilannya. Hermawan (2017) mengatakan usia produktif berpengaruh terhadap produktivitas kerjanya dalam mengelola usaha. Selain itu umur produktif umumnya memiliki semangat untuk ingin tahu dan aktif berusaha mencari informasi.

\section{Program Penyuluhan Budidaya} Perikanan yang Ramah Lingkungan

Berdasarkan hasil evaluasi terhadap program penyuluhan secara tidak langsung berupa sosialisasi budidaya perikanan yang ramah lingkungan kepada kelompok masyarakat pengawas telah menunjukkan hasilnya. Pengetahuan sasaran meningkat sebesar 33\%. Materi yang disajikan tentang cara budidaya yang tidak merusak melalui pola budidaya Wanamina (Silvofishery) mendapat respon yang baik. Menurut Sambu (2013) wanamina merupakan salah satu konsep pengelolaan yang menyeimbangkan antara upaya pelestarian dan pemanfaatan. Pola budidaya ini merupakan salah satu model pengelolaan ekosistem mangrove yang memadukan antara aspek ekologi dan aspek ekonomi. Aspek ekologi sebagai upaya melestarikan ekosistem mangrove agar berkelanjutan, sedangkan aspek ekonomi sebagai upaya untuk memanfaatkan tambak secara optimal. Sikap sangat setuju yang ditunjukkan oleh sebagian anggota kelompok terhadap pola budidaya Wanamina menunjukkan adanya ketertarikan anggota untuk menerapkan inovasi tersebut. Menurut Efendi dan Yudhati (2017) ketertarikan seseorang akan mempengaruhi tingkat keinginan orang tersebut untuk mendapatkan hal yang diinginkan. Secara umum pola silvofishery yang telah dipraktekan di Indonesia selama ini seperti yang telah dikemukakan (Bengen 2000) yaitu sebagai berikut: (1) empang parit, (2) empang parit yang disempurnakan, dan (3) komplangan. Ketiga pola tersebut masing masing mempunyai kelebihan dan kekurangan. Dengan rasio 40\% mangrove dan $60 \%$ tambak pada tambak wanamina (silvofishery) apabila dikelola secara profesional dengan menerapkan budidaya sistem polikultur udang, ikan dan kepiting produksi meningkat dan berkelanjutan.

Sikap pembudidaya terhadap materi yang telah diberikan yang sebelumnya setuju setelah diberikan penyuluhan menunjukkan sikap sangat setuju. Selama penelitian sikap anggota kelompok mengikutinya dengan semangat tinggi dan penuh keseriusan terhadap materi yang disampaikan. Hal ini terlihat dengan banyaknya pertanyaan-pertanyaan berkaitan dengan cara budidaya 
yang ramah lingkungan dan konservasi mangrove sebagai upaya pelestarian.

Dalam upaya perbaikan lingkungan dan pelestarian ekosistem mangrove keterlibatan masyarakat terutama yang berdomisili di sekitar wilayah pesisir sangat diperlukan. Pelestarian mangrove seyogyanya melibatkan masyarakat dalam pembibitan, penanaman dan pemeliharaan serta pemanfaatan yang berbasis konservasi. Pelestarian ekosistem mangrove berperan penting dalam pemberdayaan masyarakat berbasis potensi alam bagi masyarakat yang bertempat tinggal berdekatan dengan hutan mangrove. Manfaat secara langsung yang dapat dirasakan oleh nelayan adalah meningkatnya hasil tangkapan seperti, ikan, dan kepiting. Menurut Ghufron dan Kordi (2012) semakin luasnya hutan mangrove maka produksi hasil tangkapan ikan juga meningkat. Tinggi rendahnya produktivitas mangrove ditentukan beberapa faktor, di antaranya oleh fluktuasi pasang dan kimia air (Supriharyono 2000). Oleh karena itu penyuluhan pelestarian mangrove yang melibatkan masyarakat perlu terus digalakkan melalui program sadar lingkungan (DARLING) mulai dari bersih pantai, pembibitan, penanaman mangrove, rehabilitasi pantai agar kawasan konservasi Batu Doang produksi hasil budidaya dan hasil tangkapanya meningkat serta manjadi destinasi wisata mangrove.

Penyuluh yang ada di kawasan konservasi hanya 1 orang penyuluh bantu yaitu Bapak Andi Muhamad Wahyudi, S.St.Pi. Jumlah penyuluh yang tidak sebanding dengan luasnya wilayah binaan menyebabkan intensitas penyuluhan yang kurang. Hal ini yang menyebabkan kesadaran masyarakat akan arti penting pelestarian mangrove masih rendah. Menurut Wardani dan Anwarudin (2018) peran penyuluh berpengaruh signifikan terhadap penguatan kelompok dan kemandirian kelompok. Belum adanya penyuluhan yang berfokus pada pengelolaan kawasan konservasi perairan sehingga mengakibatkan rendahnya pengetahuan, sikap, dan keterampilan anggota kelompok dalam melakukan pengelolaan kawasan konservasi. Kawasan konservasi perairan memiliki manfaat dan fungsi yang sangat besar secara ekologi dan ekonomi bagi masyarakat yang tinggal di sekitar Pulau Lakkang.

\section{SIMPULAN DAN SARAN}

\section{Simpulan}

Berdasarkan hasil penelitian yang telah dilaksanakan di Pulau Lakkang Kecamatan Tallo Kota Makassar diperoleh simpulan sebagai berikut: Pengetahuan, sikap dan keterampilan anggota 
POKMASWAS setelah diberikan penyuluhan mengenai cara pembibitan, penanaman mangrove dan cara budidaya yang ramah lingkungan terjadi peningkatan. Sebagian anggota kelompok sudah memahami peran dan fungsi mangrove, terampil dalam memilih bibit,dan jenis mangrove yang sesuai dengan karakteristik habitatnya. Pembudidaya sudah mulai memahami pola budidaya Wanamina/tumpangsari yang mempunyai manfaat secara ekologi dan secara ekonomi. Sikap anggota kelompok yang pada awalnya setuju, setelah diberi penyuluhan menjadi sangat setuju melakukan pelestarian mangrove.

\section{PERSANTUNAN}

Ucapan terima kasih disampaikan kepada Ketua Program Studi Penyuluhan Perikanan, Politeknik Ahli Usaha Perikanan, yang telah memfasilitasi pendanaan penelitian ini. Ungkapan terima kasih juga disampaikan kepada Kepala Dinas Pertanian dan Perikanan Kota Makassar dan Satminkal Balai Riset Perikanan Budidaya Air Payau dan Penyuluhan Perikanan Region Pulau Sulawesi yang memberi ijin, bantuan peralatan dan tenaga lapangan selama kegiatan penyuluhan

\section{DAFTAR PUSTAKA}

Adriman, Muhammad Fauzi, Nur El Fajri, Eko Purwanto, dan Eko Prianto. 2020. "Penyuluhan Konservasi Hutan Mangrove di Desa Mengkapan Kecamatan Sungai Apit Kabupaten Siak." Journal of Rural and Urban Community Empowerment 2(1 SE-):42-49.

Bengen, Dietriech Geoffrey. 2000.

Pedoman Teknis Pengenalan dan Pengelolaan Ekosistem Mangrove. Bogor (ID): Pusat Kajian Sumberdaya Pesisir dan Lautan IPB.

Bengen, Dietriech Geoffrey. 2001. Sinopsis Ekosistem Sumberdaya Alam Pesisir dan Laut. Bogor (ID): Pusat Kajian Sumberdaya Pesisir dan Lautan IPB.

Dahuri, Rokhmin, Jacub Rais, Sapta Putra Ginting, dan M. J. Sitepu. 1996. Pengelolaan Sumberdaya Wilayah Pesisir dan Lautan Secara Terpadu. Jakarta (ID): Pradnya Paramita.

Efendi, Marwan, dan Miranti Yudhati. 2017. "Pengaruh Ekspektasi Laba terhadap Minat Berwirausaha (Studi pada Mahasiswa Angkatan 2013 STIE MBI Jakarta)." Jurnal Administrasi dan Kebijakan Publik 7(2):42-64. 
Ghufron, M., dan K. Kordi. 2012. Ekosistem Mangrove: Potensi, Fungsi, dan Pengelolaan. Jakarta (ID): Rineka Cipta.

Hermawan, Aan. 2017. "Kapasitas dan Kinerja Pengelolaan Usaha Akuakultur Anggota Kelompok Pembudidaya Ikan di Kabupaten Tasikmalaya." Jurnal Penyuluhan Perikanan dan Kelautan 11(3):160-76.

Hiariey, Lilian Sarah, dan Meitha Monita Kaihatu. 2012. Teknik Pembibitan Mangrove (Rhizophora Mucronata dan Sonneratia Alba) di Perairan Desa Passo Kecamatan Teluk Ambon Dalam. Ambon (ID).

Kusumawardani, Erika. 2012. "Pengaruh penyuluhan kesehatan terhadap tingkat pengetahuan, sikap dan praktik ibu dalam pencegahan demam berdarah dengue pada anak [Skripsi]." Universitas Diponegoro.

Mardikanto, Totok. 2011. Metoda penelitian dan evaluasi pemberdayaan masyarakat: untuk akademisi, praktisi dam peminat pemberdayaan masyarakat. Surakarta (ID): Program Pascasarjana UNS.
Mas'ud, Muhammad Yusril Aditya. 2019.

"Identifikasi Potensi dan
Permasalahan Perikanan di
Kecamatan Tallo Kota Makassar
Provinsi Sulawesi Selatan."

Mulyadi, Edi, Rudi Laksmono, dan Dewi Aprianti. 2009. "Fungsi Mangrove sebagai Pengendali Pencemar Logam Berat." Jurnal Ilmiah Teknik Lingkungan 1.

Mustanir, Ahmad, Hariyanti Hamid, dan Rifni Nikmat Syarifuddin. 2019. "Pemberdayaan Kelompok Masyarakat Desa Dalam Perencanaan Metode Partisipatif." Moderat: Jurnal IImiah IImu Pemerintahan 5(3).

Nurjaman, Agung, Sobariah, dan Lilis Supenti. 2018. "Pendampingan Kelompok Usaha Pengolahan Ikan Asin di Desa Pangandaran Kabupaten Pangandaran Provinsi Jawa Barat." Hal. 945 in Seminar Nasional Perikanan dan Penyuluhan 2018. Bogor (ID): Masyarakat Iktiologi Indonesia.

Nybakken, J. W. 1997. Marine Biology. Jakarta (ID): Gramedia.

Odum, Eugene P. 1994. Dasar-dasar Ekologi. Yogyakarta (ID): UGM Press. 
Pawestri, Elma. 2018. "Partisipasi Masyarakat dalam Pelestarian Hutan Mangrove di Desa Segarajaya. Kecamatan Tarumajaya, Kabupaten bekasi [Skripsi]." Universitas Negeri Jakarta.

Peraturan Daerah Kota Makassar Nomor 4 Tahun. 2015. Tentang RTRW Kota Makassar Tahun 2015-2034.

Peraturan Pemerintah Nomor 60 Tahun. 2007. tentang Konservasi Sumber Daya Ikan.

Priyono, Aris. 2010. "Panduan Praktis Teknik Rehabilitasi Mangrove di Kawasan Pesisir Indonesia."

Raymond, Graziano, N. Harahap, dan Soemarno. 2010. "Pengelolaan Hutan Mangrove Berbasis Masyarakat di Kecamatan Gending, Probolinggo." Agritek 18(2).
Sambu, Abdul Haris. 2013. "Optimasi Pengelolaan Tambak Wanamina (Silvofishery) di Kawasan Pesisir Kabupaten Sinjai [Tesis]." Institut Pertanian Bogor.

Supriharyono. 2000. Pelestarian dan Pengelolaan Sumberdaya Alam di Wilayah Pesisir Tropis. Jakarta (ID): Gramedia Pustaka Utama.

Undang-Undang Nomor 31 Tahun. 2004. Tentang Perikanan.

Undang-Undang Nomor 45 Tahun. 2009. tentang Perikanan.

Wardani, dan Oeng Anwarudin. 2018. "Peran Penyuluh Terhadap Penguatan Kelompok Tani dan Regenerasi Petani di Kabupaten Bogor Jawa Barat." Jurnal TABARO Agriculture Science 2(1):191-200. 